\title{
UNEPLOYMENT DYNAMICS IN CENTRAL EUROPE: A LABOUR FLOW APPROACH
}

\section{Vladislav Flek, Martina Mysíková*}

\begin{abstract}
:
We analyse labour market flows and unemployment rate dynamics in the Czech Republic (CR), Slovakia and Poland. Relative involvement of working-age individuals in movements between various labour market states appears to be approximately five times lower in Central Europe than in the U.S./UK. Compared to neighbouring countries, the CR suffers from a relatively weaker net flow of individuals from unemployment to employment. This net flow alone would cut the unemployment rate in Poland more than twice as fast as in the CR. In particular, currently unemployed Czech men, individuals with primary education, and the 55-65 age group are adversely affected by this national-specific feature of labour market flows.
\end{abstract}

Keywords: EU-SILC, labour market flows, longitudinal data, unemployment JEL Classification: J21, J64

\section{Introduction}

The period 2004-2007 in Central Europe was marked by great economic expansion. While the countries entered the period at strikingly different unemployment rates, with Poland and Slovakia suffering from enormous unemployment, around 20 per cent, and the Czech Republic at relatively comfortable one-digit figures, in only four years the unemployment rates across the region converged remarkably. In this paper we intend to discuss the observed cross-country differences in unemployment rate evolution in the light of specific patterns of labour mobility prevailing on national labour markets.

Movements of individuals between various labour market states (i.e., between employment, unemployment and inactivity) are usually referred to in the literature as gross labour market or workers flows and serve as commonly accepted proxy for labour mobility measurement. These flows involve new entries into labour market, separations from employment, or exits from unemployment. We start our analysis with description of this concept in Section 2, which includes literature overview and definition of a testable framework within which the link between unemployment rate dynamics and labour mobility can be revealed.

* Metropolitan University Prague (e-mail: vladislav.flek@mup.cz; martina.mysikova@mup.cz). Work on this paper has benefited from funding from the European Union's $7^{\text {th }}$ Framework Programme (Grant Agreement No. 613256, Project Name: "Strategic Transitions for Youth Labour in Europe"). EU-SILC data were made available to the authors on the basis of contract No. EU-SILC/2012/66 between the European Commission, Eurostat, and Metropolitan University Prague. Our thanks are due to Pavel Mertlík, Jiří Večerník, and three anonymous referees for their helpful comments. However, the authors alone remain responsible for the results. 
To our knowledge this is one of the first papers to attempt to use the longitudinal monthly data of the EU-SILC database for a comparative labour market flows analysis in Europe and thus, being relatively new, this approach requires detailed description of data. This is done in Section 3. Afterwards, in Section 4, we provide cross-country evidence on the quantity of individuals moving between various labour market states and calculate their probabilities to change the labour market status. In such a way we attempt to deliver new comparative insight into labour mobility patterns in the countries under investigation and compare our results with the existing evidence from highly developed economies.

Then we proceed in Section 5 with an examination of how the net labour market flows are linked with the evolution of unemployment rates. However, our intention is not just to deliver "a mere decomposition". In conceptual terms our net flow analysis attempts to shed some light on the quantity and structure of mismatches between labour demand and labour supply behind the observed cross-country differences in aggregate unemployment behaviour.

That is also why we deal in Section 6 with labour market flows decomposition of working-age population according to gender, education and age, and investigate their link with unemployment rates in each of these groups in the Czech Republic, Slovakia, and Poland. This should indicate the categories of Czech working-age population where the balances of net flows, and thus the dynamics of group-specific unemployment rates, are most remote from patterns prevailing in the remaining central European countries. Section 7 then concludes.

\section{Conceptual Remarks and Analytical Framework}

There is a relatively long tradition in labour market flows research: Abowd, Zellner (1985); Blanchard, Diamond (1990); or Burda, Wyplosz (1994) represent some of the pioneering analyses in the U.S./European context. Also Central Europe is covered by similar analyses - see e.g. Gora, Lehmann (1992); Bellman et al. (1995); Šrorm, Terrel (2000); Večerník (2001); Gottvald (2005); or Cazes, Nesporova (2007). Current research along these lines explores many specific directions, with the link between labour market flows and the dynamics of unemployment being one of the most influential ones. Shimer (2007); Petrongolo, Pissarides (2008); Gomes (2009); Silverstone, Bell (2010); or Dixon et al. (2011) are some of the examples of research which shares this direction.

The essence of labour marker flows analysis is as follows: At any period $t$, each individual can be either employed $(E)$, unemployed $\left(U_{t}\right)$ or inactive $\left(I_{t}\right)$. In the next period $(t+1)$ the same individual can remain in an unchanged labour market status or change it. The former situation is characterized by continuing employment $\left(E_{t} \rightarrow E_{t+1}\right)$, continuing unemployment $\left(U_{t} \rightarrow U_{t+1}\right)$, or continuing inactivity $\left(I_{t} \rightarrow I_{t+1}\right)$. In the later situation the individual status becomes subject to change in the following six ways: $\left(E_{t} \rightarrow U_{t+1}\right) ;\left(E_{t} \rightarrow I_{t+1}\right)$; $\left(U_{t} \rightarrow E_{t+1}\right) ;\left(U_{t} \rightarrow I_{t+1}\right)\left(I \rightarrow E_{t+1}\right)$; and $\left(I_{t} \rightarrow U_{t+1}\right)$. Any period $(t+1)$ thus features a certain number of individuals whose labour market status has changed since the initial period $(t)$.

The flow concept enables us also to display the link with unemployment rate dynamics. Net change in unemployment $(\Delta U)$ can most intuitively be expressed as the first difference between the stocks of unemployed $(U)$ at times $(t+1)$ and $t$. Another option common to any standard net labour market flows analysis is to make use of flow data and express $(\Delta U)$ as a balance of gross flows "in" and "out" from unemployment: 


$$
\begin{gathered}
\Delta U=\left(U_{t+1}-U_{t}\right)=[\underbrace{\left(E_{t} \rightarrow U_{t+1}\right)+\left(I_{t} \rightarrow U_{t+1}\right)}_{\mathrm{N}}]-[\underbrace{\left(U_{t} \rightarrow I_{t+1}\right)+\left(U_{t} \rightarrow E_{t+1}\right)}_{\text {OUT }}] \\
\Delta U=(I N-O U T)=[\underbrace{\left(E_{t} \rightarrow U_{t+1}\right)-\left(U_{t} \rightarrow E_{t+1}\right)}_{\text {net flow btw. U and E }}]+[\underbrace{\left(I_{t} \rightarrow U_{t+1}\right)-\left(U_{t} \rightarrow I_{t+1}\right)}_{\text {net flow btw. U and I }}]
\end{gathered}
$$

The difference $\left[\left(E_{t} \rightarrow U_{t+1}\right)-\left(U_{t} \rightarrow E_{t+1}\right)\right]$ represents the net flow of workers between unemployment and employment, and $\left[\left(I_{t} \rightarrow U_{t+1}\right)-\left(U_{t} \rightarrow I_{t+1}\right)\right]$ stands for the net flow between unemployment and inactivity. Dixon et al. (2011) formalize the contribution of these two net flows to the evolution of the unemployment rate in the following steps:

$$
\Delta\left(\frac{U}{L F}\right)=\frac{U_{t+1}}{L F_{t+1}}-\frac{U_{t}}{L F_{t}} .
$$

Formula (2) defines a change in the unemployment rate between periods $t$ and $(t+1)$ The labour force $(L F)$ consists of the employed and the unemployed; changes in the labour force are represented by $\Delta L F=\left(L F_{t+1}-L F_{t}\right)$. From formulas (1) and (1.1) we can deduce that $U_{t+1}=(I N-O U T)+U_{t}$, and therefore formula (2) can be rearranged as follows:

$$
\Delta\left(\frac{U}{L F}\right)=\frac{(I N-O U T)}{L F_{t+1}}+\frac{U_{t}}{L F_{t+1}}-\frac{U_{t}}{L F_{t}}=\frac{(I N-O U T)}{L F_{t+1}}+U_{t}\left(\frac{1}{L F_{t+1}}-\frac{1}{L F_{t}}\right) .
$$

Formula (3) expresses in percentage points which fraction of changes in the unemployment rate is due to the observed net change in unemployment (IN-OUT), and which is due to the changes in labour force. The term $(I N-O U T)$ enables to separate how the net flow of workers between unemployment and employment $(A)$, and between unemployment and inactivity $(B)$ account for changes in the unemployment rate: ${ }^{1}$

$$
\Delta\left(\frac{U}{L F}\right)=\underbrace{\frac{\left(E_{t} \rightarrow U_{t+1}\right)-\left(U_{t} \rightarrow E_{t+1}\right)}{L F_{t+1}}}_{\mathrm{A}}+\underbrace{\frac{\left(I_{t} \rightarrow U_{t+1}\right)-\left(U_{t} \rightarrow I_{t+1}\right)}{L F_{t+1}}}_{\mathrm{B}}+\underbrace{U_{t}^{\left(\frac{1}{L F_{t+1}}-\frac{1}{L F_{t}}\right)}}_{\mathrm{C}}
$$

As we argue later in the text using longitudinal EU-SILC monthly data appears to be the prospective way of how to conduct international comparisons of European labour market flows over time. However, limited by the relatively short time span, we could not explore some research advances, such as investigating the flows and unemployment dynamics over the different phases of the business cycle, to name but one.

1 Dixon et al. (2011) express the term $(C)$ as $(\Delta L F / L F) .\left(U_{t} / L_{t+1}\right)$. We find that our expression is more intuitive, while mathematically it is identical. In any case if $\triangle L F=0$, there is no contribution of changes in labour force to changes in the unemployment rate. Conversely, if $(I N-O U T)=0$, then the number of unemployed persons remains constant over time, and the unemployment rate might develop solely due to a changing labour force. 


\section{The Data}

EU-SILC is an annual survey with retrospectively stated monthly economic activity. It is harmonized by Eurostat and its longitudinal version is designed as a four-year rotational panel. The dataset available to us is EU-SILC 2008 which covers the period 1/2004$12 / 2007$. The sample design allows us to follow the developments in monthly labour market status of respondents from the initial rotational group who were surveyed for 48 consecutive months, i.e., for the maximum period.

Throughout the four-year period, there was an attrition of more than 20 per cent caused by refusals, non-contacts, untracked changes of residence, leaving the survey population, and deaths in each analysed country. These respondents are excluded from analysis irrespective of how long they stayed in the survey. The attrition rates do not differ substantially from the whole sample if labour market status of respondents at the beginning of the reference period is considered (only in Poland the attrition rate is significantly lower for employed respondents). Respondents with tertiary education mostly record significantly higher attrition rates than the whole sample and vice versa in case of primary education and higher age.

We limit our four-year samples to working-age population, i.e., to those aged between 16 and 65. This leaves us eventually with samples of 5,071 respondents for the CR, 2,099 for Slovakia, and 5,441 for Poland. By exclusively using the longest lasting initial rotational group, our final samples can be viewed as pure panels, rather than rotational ones, where all month-to-month labour market states of individuals are matched by definition. Then we apply longitudinal weights designed by Eurostat specifically for these four-year samples. ${ }^{2}$ The weighting procedure is designed to minimize the possible attrition bias.

Monthly movements of respondents between labour market states display seasonal patterns with most status changes declared between December and January. This is not surprising since employees typically tend to retire towards the end of the year, which is also the time when a large portion of quits and layoffs occurs. Some less significant peaks of status changes of respondents can typically be observed in June-July and August-September, due to seasonal jobs and labour market status changes of students. If we analysed movements of individuals between labour market states in time series, we would have to apply seasonal adjustments. Since we limit ourselves on cross-country comparisons, we believe that the use of raw monthly figures averaged over the whole investigated period can be justified.

We deal with the average monthly numbers of people involved in each of six possible labour market status changes. In this respect one has to check for possible systematic differences in the frequency of these changes across different subsets of respondents. In the CR and Slovakia 30\% of respondents experienced at least one labour market status change while it was some $35 \%$ in Poland. If we focus on these "mobile" subsamples, $84 \%-93 \%$ of respondents recorded between 1 and 3 status changes. We identify which fraction of respondents is subject to systematically a higher frequency of repeated status

2 This approach enables a 100\% month-to-month match in Slovakia. In Poland the weighting procedure of a 4-year sample still includes some respondents who stopped participating in the survey in the second, third and/or fourth year. This causes only a $96.9 \%$ level of actual matching in a weighted 4-year Polish sample. A similar yet quantitatively less relevant problem applies to the Czech sample with the actual matching level of $99.8 \%$. 
changes: Respondents with $6+$ status changes in the CR/Slovakia and 10+ in Poland can be considered as extreme outliers. ${ }^{3}$ Men, youth, and respondents with secondary education moving repeatedly between unemployment and employment usually have a stronger representation among extreme outliers than in the rest of national samples. As their fraction is negligible ( $1 \%-2 \%$ of the "mobile" subsample in all analysed countries), we do not drop them.

As EU-SILC is an annual survey with retrospectively stated monthly economic activity, respondents might not recall exactly when they changed their labour market status (e.g., when they found a job and moved from unemployment to employment). Although the precise month of such changes can be uncertain, it does not affect our results. Declaring that changes occurred between December and January although they actually occurred e.g. between February and March does not influence monthly averages for the whole period.

The monthly frequency of status changes can hide the time aggregation bias and/ or the presence of multiple transitions. This means that we are unable to capture shortterm changes (such as unemployment lasting less than two weeks) or multiple transitions (e.g., from employment to unemployment and back to employment). However, using the monthly data actually minimizes this problem in comparison with Labour Force Surveys (LFSs), the quarterly breakdown of which potentially increases the time aggregation bias and disregards even longer-lasting status changes.

The comparison of our results with those using LFSs is further limited by the fact that labour market status in LFSs is based on ILO definition while it is self-reported in EU-SILC. These two approaches are conceptually different and might influence the results. Another specificity of EU-SILC in comparison with LFSs is that the former cannot account for direct job-to-job movements. This omission might be significant in case of analysing gross labour market flows in Section 4. But the rest of our analysis is devoted to the link between net labour market flows and unemployment, where the job-to-job-flows play no role.

The reason why we use EU-SILC is simple: Although Eurostat harmonizes the national quarterly LFSs and provides an integrated dataset EU-LFS, it does not make international longitudinal datasets available for research purposes. ${ }^{4}$ The availability of national LFS longitudinal datasets is in hands of national statistical offices and studies based on such data are also rather scarce. ${ }^{5}$ That is why most of the existing flow literature explores cross-sectional quarterly LFSs data without any longitudinal structure. Any comparative European labour market flows analysis aimed at examining the longitudinal dimension has in fact to rely on alternative sources such as EU-SILC. ${ }^{6}$

3 These figures are derived from the countries' boxplots and are available from the authors upon request.

4 The only attempt available to us to use the harmonized EU-LFS for comparative labour flows analysis is represented by Cassado et al. (2011). But their research is actually based on cross-sectional EU-LFS with a retrospective question on labour market status in previous year.

5 The only exception available to us is the full longitudinal structure of quarterly LFS data for the UK - see Gomes (2009). That is why we partly refer to the UK when interpreting our results. However, cross-country comparisons of results based on monthly and quarterly data can be done only with caution.

6 Precisely for this reason Aujean et al. (2012) use EU-SILC when analysing individual transitions to and from long-term unemployment in Europe. 
Apart from potential drawbacks linked with using EU-SILC, there are also some positive side-effects. As noted earlier, time aggregation bias appears to be reduced in comparison with LFSs. In addition, longitudinal EU-SILC enables more meaningful comparisons between European countries and the U.S. where labour flow analyses are as a rule based on longitudinal monthly data. It is plausible to use the U.S. as a reference country because the American labour market is believed to be more mobile (flexible) than those of European economies. ${ }^{7}$ Using the longitudinal EU-SILC we can test in a specific way the validity of this assumption and support/reject it by new quantifications for Central European countries.

\section{Gross Labour Market Flows in a Comparative Perspective}

Based on 47 month-to-month observations in the three countries, we calculate the average monthly number of individuals involved in labour market status changes (Figures 1-3). In all countries analysed most individuals move every month on average from unemployment to employment, followed by movements in the opposite direction. Individuals moving in both directions between employment and inactivity form with equal uniformity the second quantitatively most relevant group, while mutual movements between unemployment and inactivity are the absolutely lowest ones. This signals the presence of similar patterns of labour mobility in structural terms across all analysed countries (see also Table 1).

\section{Figure 1}

Gross Labour Market Flows in the Czech Republic (monthly averages, 2004-2007)

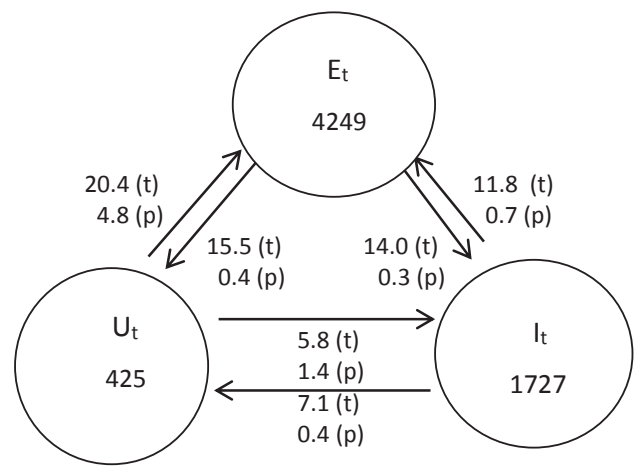

Notes: Employment (E); Unemployment (U); Inactivity (I); number of people in thousands (t); Probability of changing labour market status next month in per cent (p). Quits, layoffs and redundancies $(E \rightarrow U)$ new hires and recalls $(U \rightarrow E)$ retirements and withdrawals $(E \rightarrow I)$ retirements and withdrawals $(U \rightarrow I)$ entrants and re-entrants $(I \rightarrow E)$; entrants and re-entrants $(I \rightarrow U)$.

Source: EU-SILC LONGITUDINAL UDB 2008, Version 3 of August 2011; own calculations from weighted matched sample.

7 Some Western European labour markets which could serve for reference purposes, such as the German one, are not included in the longitudinal EU-SILC 2008. In other potentially illustrative cases such as the UK, there are some obstacles for the results to remain fully comparable (e.g. a different construction of longitudinal weights). 


\section{Figure 2}

Gross Labour Market Flows in Slovakia (monthly averages, 2004-2007)

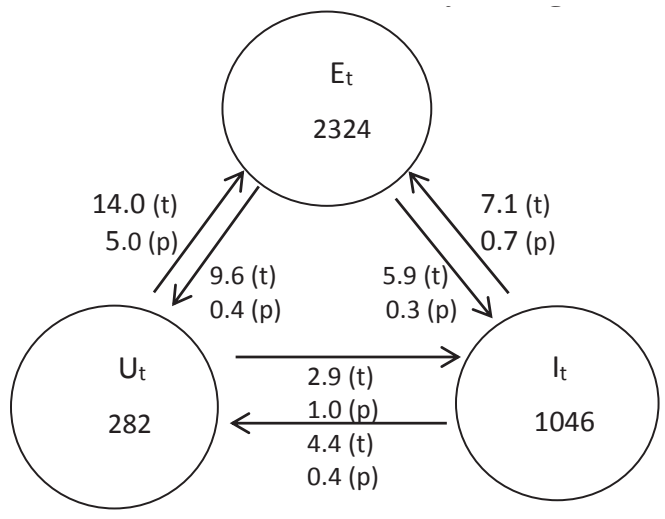

Notes and source: See Figure 1.

Figure 3

Gross Labour Market Flows in Poland (monthly averages, 2004-2007)

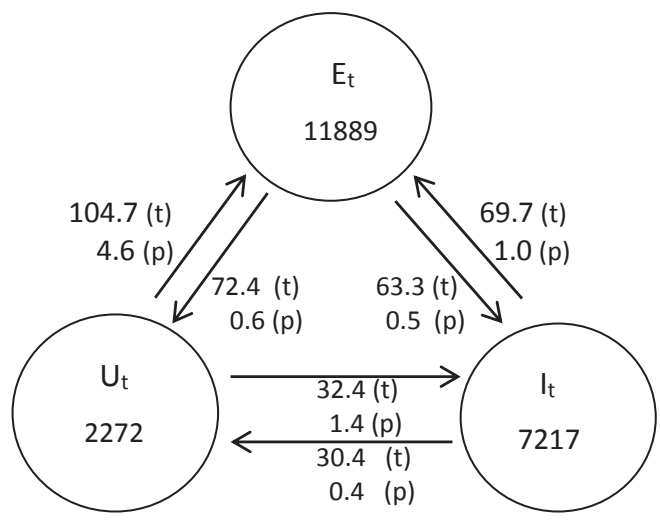

Notes and source: See Figure 1.

Row totals in Table 1 evidence that in the CR 1.17 per cent of working-age individuals change on average their labour market status every month. The respective figures are 1.19 for Slovakia and 1.75 for Poland. All three countries thus appear to display rather modest differences: The respective difference between the Polish and Czech labour market, or in other words between the most "fluid" and the most "tight" labour market, amounts to just around half a percentage point $(1.75 \%-1.17 \%)$. 
Table 1

Gross Labour Market Flows in Central Europe (monthly averages, 2004-2007)

\begin{tabular}{|l|c|c|c|c|c|c|}
\hline & $\left(E_{t} \rightarrow U_{t+1}\right)$ & $\left(E_{t} \rightarrow I_{t+1}\right)$ & $\left(U_{t} \rightarrow E_{t+1}\right)$ & $\left(U_{t} \rightarrow I_{t+1}\right)$ & $\left(I_{t} \rightarrow E_{t+1}\right)$ & $\left(I_{t} \rightarrow U_{t+1}\right)$ \\
\hline CR & 0.24 & 0.23 & 0.32 & 0.09 & 0.18 & 0.11 \\
\hline Slovakia & 0.26 & 0.16 & 0.38 & 0.08 & 0.19 & 0.12 \\
\hline Poland & 0.34 & 0.30 & 0.49 & 0.15 & 0.33 & 0.14 \\
\hline
\end{tabular}

Notes: In per cent of working-age population (16-65); weighted matched sample.

Source: EU-SILC LONGITUDINAL UDB 2008, Version 3 of August 2011; own calculations.

The CR appears to have a slightly weaker gross flow from unemployment to employment $\left(U_{t} \rightarrow E_{t+1}\right)$ in relative terms: While in the CR it involves on average some 0.3 per cent of working-age individuals per month, in Slovakia and Poland the respective figures are 0.4 and 0.5 per cent. We still have to ask later in the text about the relevance of this finding with respect to the cross-country differences in unemployment rate dynamics.

Results in Table 1 signal a considerably lower degree of mobility on Central European labour markets compared to the U.S./UK. In the U.S. between $5 \%-7 \%$ of working-age individuals change on average their labour market status every month, depending on the analysed period and author. The quarterly results for the UK are similar to the U.S. There is also structural dissimilarity between central European and UK/U.S. patterns of labour mobility. While in Central Europe movements of individuals between unemployment and employment predominate, in the U.S. and in the UK those between employment and inactivity (and vice versa) are the most relevant ones. ${ }^{8}$

Figures 1-3 involve transition probabilities $(p)$ at which, on average, each individual is faced with a chance of changing their labour market status next month. ${ }^{9}$ The results concerning Central European labour markets are highly similar, and at the same time remarkably different from those obtained for the U.S. or the UK. In Central Europe the transition probability that an unemployed will become employed next month ranges between 4.6 per cent and 5.0 per cent. Yet, this probability in the U.S. and the UK is much higher: Fallick, Fleischman (2004) established its average monthly value for the U.S. in 1996-2003 at 28.3 per cent; Gomes (2009) reported that its quarterly average value in 1996-2007 in UK was 27.8 per cent. This leaves Central European unemployed with

8 See Gomes 2009 for an overview. The results for the U.S. refer to averages derived from one or even two decades of monthly observations, while our data cover just a four-year period 2004-2007. When we refer to the UK, one has to consider the quarterly structure of the UK data which might generate over/underestimated results.

9 These probabilities can be expressed as first-order Markov transitions where the individual finds $\mathrm{him} /$ herself in a new (or initial) labour market status at time $(t+1)$, depending on his/her labour market status at time $t$. For instance, $\left(U_{t} \rightarrow E_{t+1}\right) / U_{t}$ indicates the probability to exit unemployment and move to employment. All possible transitions form a $3 \times 3$ matrix where the diagonal terms represent unchanged labour market states. Each row involves two off-diagonal terms indicating status transitions. In a fully tight labour market the off-diagonal terms equal zero. Conversely, in a totally fluid labour market with $100 \%$ transitions of individuals between states, the diagonal terms would be zero. See e.g. Abraham, Shimer (2001) or Silverstone, Bell (2010) for detail. 
a striking one-in-five chance of receiving a job in the next period compared to their U.S. (or UK) counterparts. ${ }^{10}$

The probability of losing job and entering the pool of unemployed next month ranges between 0.4 per cent and 0.6 per cent in Central Europe. This is again much less than in the UK and the U.S., where in both cases this probability reaches 1.3 per cent - see Fallick, Fleischman (2004); Gomes (2009). It follows that the risk of losing a job and becoming unemployed next period is on average two or even three times lower in Central Europe.

\section{Labour Market Flows and Unemployment}

In Table 2 net changes in unemployment $(\Delta U)$ are presented as the balance between the two "unemployment-related" net flows. In the CR a net decline in unemployment totals on average some 3,500 persons every month, in Slovakia and Poland 2,900 and 34,300 , respectively. Table 2 demonstrates in second column that the net flow from unemployment to employment is the key feature behind the country-specific net declines in unemployment. In fact in the CR and Slovakia it is the only net flow cutting down the total number of unemployed. This is to be attributed to the simultaneous presence of net flows from inactivity to unemployment.

Table 2

Net Changes in Unemployment (monthly averages, 2004-2007)

\begin{tabular}{|l|c|c|c|}
\hline & $\begin{array}{c}\text { Average monthly } \\
\text { net change in } \\
\text { unemployment }\end{array}$ & $\begin{array}{c}\text { Average monthly net flows } \\
\text { between unemployment } \\
\text { and employment }\end{array}$ & $\begin{array}{c}\text { Average monthly net flows } \\
\text { between unemployment } \\
\text { and inactivity }\end{array}$ \\
\hline CR & $\Delta U$ & {$\left[\left(E_{t} \rightarrow U_{t+1}\right)-\left(U_{t} \rightarrow E_{t+1}\right)\right]$} & {$\left[\left(I_{t} \rightarrow U_{t+1}\right)-\left(U_{t} \rightarrow I_{t+1}\right)\right]$} \\
\hline Slovakia & $-3,576$ & $-4,811$ & 1,235 \\
\hline Poland & $-2,913$ & $-4,398$ & 1,485 \\
\hline
\end{tabular}

Notes: Number of people (16-65); weighted matched sample. Negative values represent net flows from unemployment to employment ( $2^{\text {nd }}$ column), and from unemployment to inactivity ( $3^{\text {rd }}$ column).

Source: EU-SILC LONGITUDINAL UDB 2008, Version 3 of August 2011; own calculations.

The rightmost column in Table 2 shows that, in both these countries, more people move on average every month from inactivity to unemployment $\left(I_{t} \rightarrow U_{t+1}\right)$ than in the opposite direction $\left(U_{t} \rightarrow I_{t+1}\right)$. This net flow alone would therefore account for an average monthly increase in the total number of unemployed by some 1,200 persons in the CR

10 Our results do not account for the impact of previous unemployment duration on individual probability of becoming employed next period. Abraham, Shimer (2001) or Aujean et al. (2012) use duration data and find that both in the U.S. and the European Union the chance to find job is a decreasing function of previous unemployment duration. When we refer to transition probabilities found in other analyses, we have strictly in mind only those which are calculated in line with ours, i.e. without duration data. 
and 1,500 in Slovakia. In contrast, Poland is the only country experiencing a net flow from unemployment to inactivity, which accounts for total unemployment diminishing on average by some 2,000 persons every month (see third column in Table 2). This structural specificity is another, albeit partial, factor to be considered later in the text when the crosscountry differences in unemployment rate dynamics are discussed.

Results in Table 2 can be considered as quantitative evidence of the crucial role the workers moving from unemployment to employment have on net changes in unemployment in Central European economies. Nonetheless, when relying solely on such figures, it would remain somewhat unclear how exactly did the corresponding gross/net flows contribute to the observed reductions in national unemployment rates. That is why the links between labour market flows and the dynamics of unemployment rates have to be quantified explicitly and in a manner enabling international comparisons.

\section{Table 3}

Changes in the Unemployment Rate (monthly averages, 2004-2007)

\begin{tabular}{|c|c|c|c|c|}
\hline & $\begin{array}{l}\text { Av. monthly } \\
\text { change in the } \\
\text { unemployment } \\
\text { rate }\end{array}$ & $\begin{array}{l}\text { Contribution of } \\
\text { net av. monthly } \\
\text { flows between } \\
\text { unemployment } \\
\text { and employment }\end{array}$ & $\begin{array}{l}\text { Contribution of } \\
\text { net av. monthly } \\
\text { flows between } \\
\text { unemployment } \\
\text { and inactivity }\end{array}$ & $\begin{array}{c}\text { Contribution } \\
\text { of av. monthly } \\
\text { change in labour } \\
\text { force }\end{array}$ \\
\hline & & $A$ & B & $C$ \\
\hline CR & -0.0737 & -0.1030 & 0.0264 & 0.0029 \\
\hline Slovakia & -0.1228 & -0.1686 & 0.0569 & -0.0111 \\
\hline Poland & -0.2469 & -0.2275 & -0.0144 & -0.0050 \\
\hline US* & -0.0560 & -0.1580 & 0.1040 & -0.0020 \\
\hline Australia** & -0.0630 & -0.2880 & 0.2290 & -0.0040 \\
\hline
\end{tabular}

Notes: In percentage points; *results for recovery period July 2003-March 2007; ${ }^{* *}$ results for recovery period October 2001-December 2003.

Sources: EU-SILC LONGITUDINAL UDB 2008, version 3 of August 2011; own calculations; Dixon et al. (2011, pp. 28-29) for the US, Dixon et al. (2004, pp. 23-24) for Australia.

The three components on the RHS in formula (4) are calculated in Table 3 and specify, in percentage points, the contributions of the corresponding flows to the monthly average changes in the unemployment rate. The term $A$, if negative, announces the contribution of a net flow of workers from unemployment to employment to cutting the unemployment rate. Negative $B$, on the other hand, marks the contribution of a net flow from unemployment to inactivity to declines in the unemployment rate. Finally, the term $C$ indicates the contribution of changes in labour force to changes in the unemployment rate: If negative, it indicates a decline in the unemployment rate due to increasing labour force.

Table 3 shows that the steepest decline in the unemployment rate is witnessed in Poland with a monthly average of 0.25 percentage points. Slovakia scores twice as worse with its 
mere 0.12 percentage points and the CR three and a half times as worse with only 0.07 percentage points. The common major element contributing to declines in national rates of unemployment is a net flow from unemployment to employment (see negative values in column $A$ ). The contribution of elements $(B+C)$ is much less relevant if not negligible.

Cross-country differences in the downward dynamics of the unemployment rate are closely linked with different strengths of net flows of workers from unemployment to employment $(A)$ : In Poland, net flow of workers from unemployment to employment $(A)$ alone cuts the monthly unemployment rate on average by some 0.23 percentage points, while in the CR the same net flow contributes on average only by 0.10 percentage points. Thus the net flow of workers from unemployment to employment alone contributes to diminishing the unemployment rate in Poland more than twice as fast as in the CR.

Unemployment response to economic recovery in the U.S. over a comparable period was weaker than in Central Europe (see Table 3). According to Dixon et al. (2011), average monthly decline in the U.S. unemployment rate represented just -0.056 percentage points per month, of which the contribution of the net flow from unemployment to employment $(A)$ accounted for -0.158 percentage points. The contribution of the net flow from inactivity to unemployment $(B)$ actually represented 0.104 percentage points. A relatively much higher net inflow into unemployment from inactivity $(B)$ thus accounts decisively for a relatively lower downward unemployment rate dynamics in the U. S. compared with Central Europe. Similar conclusions apply even more to Australia, the second country with available calculations.

To sum up, in all Central European countries more people were moving on average every month from unemployment to employment than in the opposite direction, and this was the major net flow contributing to the observed declines in the unemployment rates. But in the CR this contribution was much weaker in relative terms, even in comparison with the U. S. To account for this apparent Czech specificity, a more detailed analysis is needed to identify the categories of Czech working-age individuals where the balances of net flows, and thus the dynamics of group-specific unemployment rates, are most remote from patterns prevailing in the remaining countries. To our knowledge no decompositions of this sort have been made to date and there are no results available for reference purposes.

\section{Unemployment Rates and Labour Market Flows of Specific Population Groups}

The male unemployment rate in the $\mathrm{CR}$ is declining on average by 0.06 percentage points per month, female by 0.09 percentage points, i.e. Czech female unemployment rate is diminishing by one third more rapidly than the male one (Table 4). Column $A$ in Table 4 demonstrates that this is mainly to be attributed to a relatively stronger female net flow from unemployment to employment compared to male. Such result differs both from Slovakia and Poland. In these countries unemployment rates of men are declining more rapidly than those of women because of stronger male net flows from unemployment to employment compared to female. Also note that net male flows from unemployment to employment $(A)$ in the CR contribute to cutting their unemployment rate three or even four times less than in Slovakia or Poland. 
Table 4

Changes in the Unemployment Rate: Gender Decomposition (2004-2007)

\begin{tabular}{|l|l|c|c|c|c|}
\hline & & $\begin{array}{c}\text { Average monthly change } \\
\text { in the unemployment rate }\end{array}$ & $\boldsymbol{A}$ & $\boldsymbol{B}$ & $\boldsymbol{C}$ \\
\hline \multirow{2}{*}{ CR } & Male & -0.0610 & -0.0726 & 0.0136 & -0.0020 \\
& Female & -0.0865 & -0.1403 & 0.0422 & 0.0116 \\
\hline \multirow{2}{*}{ Slovakia } & Male & -0.1747 & -0.2050 & 0.0406 & -0.0104 \\
& Female & -0.0650 & -0.1281 & 0.0751 & -0.0120 \\
\hline \multirow{2}{*}{ Poland } & Male & -0.2591 & -0.2734 & 0.0305 & -0.0163 \\
& Female & -0.2320 & -0.1784 & -0.0626 & 0.0089 \\
\hline
\end{tabular}

Notes: In percentage points; weighted matched sample.

Source: EU-SILC LONGITUDINAL UDB 2008, Version 3 of August 2011; own calculations.

The CR is the only country with a net flow of least qualified workers from employment to unemployment (see column $A$ in Table 5). The net flow $(A)$ alone accounts for an average increase by 0.005 percentage points per month in the unemployment rate of the least qualified Czech workers. The results for Slovakia and Poland in this respect are quite opposite, with net flows of primary education workers from unemployment to employment, which then alone contributes to average monthly declines in their specific unemployment rates by 0.26 percentage points in Poland, and by 0.37 percentage points in Slovakia. These results are striking since they reveal that only in the CR the net flow of least qualified workers between unemployment and employment behaves counter-cyclically.

\section{Table 5}

Changes in the Unemployment Rate: Educational Decomposition (2004-2007)

\begin{tabular}{|l|l|c|c|c|c|}
\hline & & $\begin{array}{c}\text { Average monthly change } \\
\text { in the unemployment rate }\end{array}$ & $\boldsymbol{A}$ & $\boldsymbol{B}$ & $\boldsymbol{C}$ \\
\hline \multirow{3}{*}{ CR } & Primary & -0.0607 & 0.0050 & -0.1542 & 0.0885 \\
& Secondary & -0.0825 & -0.1240 & 0.0390 & 0.0025 \\
& Tertiary & 0.0015 & -0.0400 & 0.0434 & -0.0020 \\
\hline \multirow{3}{*}{ Slovakia } & Primary & -0.3518 & -0.3724 & -0.1256 & 0.1462 \\
& Secondary & -0.1182 & -0.1521 & 0.0411 & -0.0072 \\
& Tertiary & -0.0260 & -0.1918 & 0.1755 & -0.0097 \\
\hline \multirow{3}{*}{ Poland } & Primary & -0.4177 & -0.2613 & -0.2445 & 0.0881 \\
& Secondary & -0.2691 & -0.2494 & -0.0172 & -0.0025 \\
& Tertiary & -0.0146 & -0.1273 & 0.1246 & -0.0119 \\
\hline
\end{tabular}

Notes and Source: See Table 4. 
Another (and even more striking) cross-country difference concerns the population group aged between 55 and 65: In the CR, the net flow of this category of workers is from employment to unemployment, and this net flow alone would contribute to an increase in the specific monthly unemployment rate of this group on average by 0.13 percentage points (column $A$ in Table 6). In contrast, Poland (Slovakia) witnesses a net flow $(A)$ of elderly workers from unemployment to employment, which alone would contribute to a monthly average decrease in their specific unemployment rate by 0.06 percentage points ( 0.14 percentage points). Again, only in the CR the net flow between unemployment and employment (and the dynamics of the specific unemployment rate as a whole) of elderly workers appears to be of a rather counter-cyclical nature.

\section{Table 6}

Changes in the Unemployment Rate: Age Decomposition (2004-2007)

\begin{tabular}{|l|c|c|c|c|c|}
\hline & & $\begin{array}{c}\text { Average monthly } \\
\text { change in the } \\
\text { unemployment rate }\end{array}$ & A & B & C \\
\hline \multirow{3}{*}{ CR } & $19-24$ & -0.3080 & -0.8128 & 0.9244 & -0.4196 \\
& $25-54$ & -0.0934 & -0.1054 & 0.0138 & -0.0018 \\
& $55-65$ & 0.0013 & 0.1303 & -0.2056 & 0.0765 \\
\hline \multirow{3}{*}{ Slovakia } & $19-24$ & -0.5075 & -1.0607 & 1.1378 & -0.5845 \\
& $25-54$ & -0.1118 & -0.1147 & 0.0095 & -0.0066 \\
& $55-65$ & -0.1723 & -0.0630 & -0.1766 & 0.0673 \\
\hline \multirow{3}{*}{ Poland } & $19-24$ & -0.7046 & -0.8556 & 0.8925 & -0.7416 \\
& $25-54$ & -0.2444 & -0.1945 & -0.0517 & 0.0019 \\
& $55-65$ & -0.2148 & -0.1406 & -0.2092 & 0.1350 \\
\hline
\end{tabular}

Notes and Source: See Table 4.

\section{Conclusion}

A relatively modest share of working-age individuals (between 1-2 per cent) is involved in movements between various labour market states in Central Europe. This result is approximately five times lower than one in the U.S. or in the UK. In addition the fairly low degree of mobility in Central European labour markets is confirmed by the analysis of transition probabilities. Here the differences in comparison with the U.S./UK are again of a similar magnitude, above all with respect to the individual probability of moving from unemployment to employment and vice versa.

The analysis confirms the major contribution of the net flow of workers from unemployment to employment to the downward dynamics of total unemployment. In the $\mathrm{CR}$ and Slovakia this is the sole labour mobility channel contributing to cutting down the total number of unemployed. The same net flow further needs to be taken into account when analysing the sources of changes in the unemployment rate. It contributes most remarkably to unemployment rate declines in all Central European countries and also 
accounts for the majority of cross-country differences in unemployment rate dynamics. This net flow alone would diminish the unemployment rate in Poland more than twice as fast as in the CR.

Our results suggest that the CR is lagging behind in creating job opportunities for unemployed men, and even more so for unemployed least qualified and elderly individuals. Only in this country more primary education and elderly workers had lost their jobs and entered the pool of unemployed compared to the amount of those who had left unemployment and moved into employment. Thus the net flows of those workers were from employment to unemployment, with an adverse impact on their specific unemployment rates and on aggregate unemployment rate dynamics as a whole. Such results (above all their counter-cyclical character) are unique within the context of strong economic expansion in Central Europe.

Remarkably lower capacity of the Czech labour market to absorb particularly the least qualified and elderly unemployed workers signals the presence of more persistent structural mismatches between labour demand and supply with respect to these categories of workers. Our results thus contribute to understanding why structural unemployment diminished according to OECD (2012) only by less than one percentage point in the CR during the period 2004-2007 while it declined by 2.7 percentage points in Slovakia and by 5.7 percentage points in Poland. With reference to a more complex view provided by e.g. CNB (2008), our findings are also helpful in understanding why the long-term unemployment rate declined in the CR only by 1.6 percentage point in comparison with 3.5 percentage points in Slovakia and 5.4 percentage points in Poland.

This should trigger a response in active labour market policy, the system of benefit provision, labour taxation, supporting more flexible forms of employment contracts, and stronger measures against illegal work in the Czech Republic. Shortcomings in these institutional areas are typically responsible, at least to a certain extent, for insufficient dynamics of labour market flows, above all with respect to flows from unemployment to employment.

\section{References}

Abraham, K. G., Shimer, R. (2001), "Changes in Unemployment Duration and Labor Force Attachment." National Bureau of Economic Research Working Paper No. 8513.

Aujean, L., Tchipeva, T., Pescher, J. (2012), "The Dynamics of Long-Term Unemployment." in: Employment and Social Developments in Europe. Brussels: European Commission.

Bellmann, L., Estrin, S., Lehmann, H., Wadsworth, J. (1995), "The East German Labour Market in Transition: Gross Flow Estimates from Panel Data." Journal of Comparative Economics, Vol. 20, No. 2, pp. 139-170.

Blanchard, O. J., Diamond, P. (1990), "The Cyclical Behavior of Gross Flows of US Workers." Brookings Papers on Economic Activity, Vol. 21, No. 2, pp. 85-156.

Burda, M., Wyplosz, Ch. (1994), "Gross Worker and Job Flows in Europe." European Economic Review, Vol. 38, No. 6, pp. 1287-1315.

Cassado, J. M., Fernandez, C. Jimeno, J. F. (2011), "Labour Market Flows in the European Union." Paper presented at the GESIS $2^{\text {nd }}$ EU-Microdata User Conference, Manheim.

Cazes, S., Nesporova, A., eds. (2007), Flexicurity: A Relevant Approach in Central and Eastern Europe. Geneva: International Labour Organisation. 
CNB (2008), Analyses of the Czech Republic's Current Economic Alignment with the Euro area. Chapter 2: Adjustment mechanisms. Prague: Czech National Bank, Monetary Department.

Dixon, R., Freebairn, J., Lim, G. C. (2011), "Net Flows in the U.S. Labor Market, 1990-2010.” Monthly LaborReview (February), pp. 25-32.

(2004), "A Framework for Understanding Changes in the Unemployment Rate in a Flows Context: An Examination of Net Flows in the Australian Labour Market." University of Melbourne Department of Economics Research Paper No. 910.

Fallick, B., Fleischman, C. A. (2004), "Employer-to-Employer Flows in the US Labor Market: The Complete Picture of Gross Worker Flows." Board of Governors of the Federal Reserve System Finance and Economics Discussion Series No. 34.

Gomez, P. (2009), "Labour Market Flows: Facts from the United Kingdom." Bank of England Working Paper No. 367.

Gora, M., Lehmann, H. (1992), "Flow and Stock Analysis of Polish Unemployment: January 1990June 1991." Labour, Vol. 6, No. 1, pp. 87-120.

Gottvald, J. (2005), "Czech Labour Market Flows 1993-2003." Czech Journal of Economics and Finance, Vol. 55, Nos. 1-2, pp. 41-53.

OECD (2012), Economic Outlook - Annual Projections, No. 92. Paris. Retrieved from: http://stats.oecd.org/index.aspx?queryid=40203

Petrongolo, B., Pissarides Ch. A. (2008), "The Ins and Outs of European Unemployment." American Economic Review, Vol. 98, No. 2, pp. 256-262.

Shimer, R. (2007), "Reassessing the Ins and Outs of Unemployment." National Bureau of Economic Research Working Paper No. 13421.

Silverstone, B., Bell, W. (2010), “Labour Market Flows in New Zealand: Some Questions and Some Answers." Paper presented at the 51st Conference of the New Zealand Association of Economists, Auckland.

Sorm, V., Terrel, K. (2000), "Sectoral Restructuring and Labor Mobility: A Comparative Look at the Czech Republic." Journal of Comparative Economics, Vol. 28, No. 3, pp. 431-455.

Večerník, J. (2001), "Labour Market Flexibility and Employment Security - Czech Republic." International Labour Organisation Employment Paper No. 27. 